\title{
ISOLATION AND CHARACTERIZATION OF TWO NOVEL DEGRADANT PRODUCTS IN ITRACONAZOLE BY USING PREP-HPLC, HRMS AND NMR
}

\author{
Santhosh Guduru ${ }^{1,2}$, V.V.S.R.N. Anji Karun Mutha ${ }^{1,2}$, Muralidharan \\ Kaliyaperumal $^{1}$, Chidananda Swamy Rumalla ${ }^{1,}$, Raghu Babu Korupolu ${ }^{2}$ \\ and Kishore Babu Bonige ${ }^{2}$ \\ ${ }^{1}$ Department of Medicinal Chemistry, GVK Biosciences Pvt. Ltd, IDA Mallapur, \\ Hyderabad, Telangana, India-500076 \\ ${ }^{2}$ Department of Engineering Chemistry, Andhra University, \\ Visakhapatnam, A.P., India-530003 \\ *E-mail: chidanand_swamy@yahoo.co.in
}

\begin{abstract}
To in-line with the ICH guideline Q1A(R2), Itraconazole was subjected to acidic ,basic and oxidative stress . Drug was stable in all the conditions except oxidation stress. Separated the two oxidative degradation products, by using gradient elution, C8 column on preparative HPLC and structural elucidation was performed by using 1D \& 2D NMR spectroscopic studies and mass analysis. Those are recognized as 1-(4-((2-((1H-1,2,4-triazol-1-yl)methyl)-2(2,4-dichlorophenyl)-1,3-dioxolan-4-yl) methoxy) phenyl)-4-(4-(1-(sec-butyl)-5-oxo-1,5-dihydro-4H-1,2,4-triazol4-yl)phenyl)piperazine 1,4-dioxide(DP-1), 1-(4-((2-((1H-1,2,4-triazol-1-yl)methyl)-2-(2,4-dichlorophenyl)-1,3dioxolan-4-yl)methoxy)phenyl)-4-(4-(1-(sec-butyl)-5-oxo-1,5-dihydro-4H-1,2,4-triazol-4-yl)phenyl) piperazine 1oxide (DP-2).These degradents are innovative impurities which are found first time in this product. Moreover, the degradation mechanism from Itraconazole to DP-1 and DP-2 was also proposed.
\end{abstract}

Keywords: Itraconazole, prep-HPLC, Impurities, Mass Spectrometry, NMR, Isolation and characterization.

(C) RASĀYAN. All rights reserved

\section{INTRODUCTION}

Itraconazole (ITZ) is a broad-spectrum, synthetic triazole antifungal agent. Chemically it is (4-[4-[4-[4[[2-(2-(2,4-Dichlorophenyl)-2-1H-1,2,4-triazol-1-ylmethyl)-1,3-dioxolan-4-yl] methoxy] phenyl]-1piperazinyl]phenyl]-2, 4-dihydro-2-(1-methylpropyl)-3H-1,2,4-triazol-3-one. It is used in the treatment of a variety of fungal infections.

Forced degradation studies of a drug candidate is an important part of drug discovery and drug development stages ${ }^{1-3}$ and are widely used to predict drug stability problems and identify degradation products or potential impurities. The advantage of stress testing under different conditions is that it provides more comprehensive information on the degradation pathway of the drug. When a drug degrades, it may result in the loss of drug activity and degradation products may elicit possible adverse reactions. The international conference on harmonization guidelines Q1A (R2) require that all degradation products formed during the forced degradation of a drug under various stress conditions should be characterized. ${ }^{4}$ Therefore, degradation product and impurity profiling is one of the most important areas of modern pharmaceutical analysis.

Stress studies are conducted to create degradation /debasement items in greater quantities as they are framed in low proportions $(0.1-0.5 \%, \mathrm{w} / \mathrm{w})$ during storage. ${ }^{5}$ and still, after all that, a considerable lot of the occasions, it is fairly hard to disconnect these contaminations from the focused on blend because of their low sums and subject them to unearthly investigations for basic data.

Rasayan J. Chem., 12(1), 114 -122(2019)

http://dx.doi.org/10.31788/RJC.2019.1215077

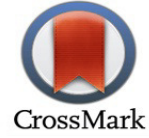


A few analytical and bioanalytical methods have been reported in the literature for the determination of ITZ. It includes estimation of ITZ alone or ITZ and it's in vivo metabolites in biological matrices. ${ }^{6-12}$

A comprehensive study has been undertaken to isolate and characterize these impurities by prep HPLC and spectroscopic techniques. This research article describes the separation, identification, isolation and characterization of two impurities that are present in the range of $6.95 \%$ and $9.49 \%$ by peak area in the bulk drug of Itraconazole.

\section{Chemicals}

\section{EXPERIMENTAL}

Itraconazole API was procured from one of the manufacturing units in Hyderabad, Acetonitrile (Merck), Formic acid (Alfa Aesar), Dimethyl sulfoxide- $\mathrm{d}_{6}$ containing 0.03\% (v/v) TMS (Cambridge isotope limited) and Milli-Q grade water was used for the study

\section{Liquid Chromatography-Mass Spectrometry}

HPLC with ACQUITY BEH C18 Column consists of $2.1 \mathrm{~mm} \times 50 \mathrm{~mm}$ dimensions and $1.7 \mu$ film thickness is used for the study with gradient program as Mobile phase A: $0.1 \%$ formic acid (Aq); Mobile phase B: Acetonitrile; T/\% of B: 0.0/2.0, 0.2/2.0, 1.5/98, 2.6/98, 2.61/2.0, 3.2/2.0 at wavelength $215 \mathrm{~nm}$

\section{Preparative HPLC}

The preparative HPLC used for the study is Waters PDA detector module 2998 at $215 \mathrm{~nm}$ with a symmetry-C8 column of $300 \mathrm{X} 19 \mathrm{~mm}$ dimensions and $7 \mu$ also used the gradient program as mobile phase A: $0.1 \%$ formic acid(Aq); mobile phase $\mathrm{B}$ : Acetonitrile: $\mathrm{T} \%$ of $\mathrm{B}$ : $0.0 / 10,1 / 10,10 / 60,12 / 60,12.1 / 98,14 / 98,14.1 / 10$

\section{High-Resolution Mass Spectrometry and MS/MS}

HRMS study was conducted by using waters micro mass Q-TOF instrument in the positive mode with Mass lynx software and ESI as an ion source. The Leucine encephalin (m/z: 555.62268 Da) was chosen as an internal standard to have accurate results. SHIMADZU SIL HTC 5500 Qtrap was taken for MS/MS and water c18 column with dimensions $250 \mathrm{X} 3.0 \mathrm{~mm}$ of $5.0 \mu$ particle size was used for chromatographic technique with a flow rate of $0.5 \mathrm{~mL} / \mathrm{min}$, also used the gradient program as mobile phase A: $0.1 \%$ formic $\operatorname{acid}(\mathrm{Aq})$; mobile phase B: Acetonitrile:

\section{Nuclear Magnetic Resonance Spectroscopy}

The ${ }^{1} \mathrm{H},{ }^{13} \mathrm{C}$ NMR and 2D NMR spectra of oxidative degradation impurities were recorded in DMSO- $\mathrm{d}_{6}$ solvent on Bruker $500 \mathrm{MHz}$ Avance -III HD NMR spectrometer equipped with BBO Probe. The ${ }^{1} \mathrm{H}$ and ${ }^{13} \mathrm{C}$ chemical shifts are reported on $\delta$ scale in ppm, relative to tetra methyl silane (TMS) as an internal standard. The spectra were set to $\delta 0.00 \mathrm{ppm}$ in ${ }^{1} \mathrm{H}$ NMR (TMS) and $\delta 39.50 \mathrm{ppm}$ in ${ }^{13} \mathrm{C}$ NMR (DMSO$\left.\mathrm{d}_{6}\right)$.

\section{Hydrolytic stress methods}

Oxidation degradation The drug was subjected to stress as per ICH guideline Q1A (R2) to identify the potential degradants those could be generated during the storage. Oxidation degradation studies were carried out as per the guidelines of ICH. $200 \mathrm{mg}$ of standard drug was suspended in $10 \mathrm{ml}$ of $5 \% \mathrm{H}_{2} \mathrm{O}_{2}$ and stirred at room temperature for $24 \mathrm{~h}$ to study oxidation degradation and stirring was continued till $48 \mathrm{~h}$ to achieve sufficient degradation.

\section{RESULTS AND DISCUSSION}

Even though the required impurities were formed in $24 \mathrm{hrs}$ time under stirring of media, it was continued up to $48 \mathrm{hrs}$ to get the more quantity of the impurity. $1 \mathrm{~mL}$ of the above degradation solution was taken into methanol followed by diluted with mobile phase and subjected to LC-MS system and observed two degradant impurities (Fig.-1). Furthermore, no degradations were found in other instances and oxidation degradation solution was sent/diverted for isolation/purification 
RASĀYAN J. Chem.

Vol. 12 | No. 1 |114 - 122| January - March | 2019

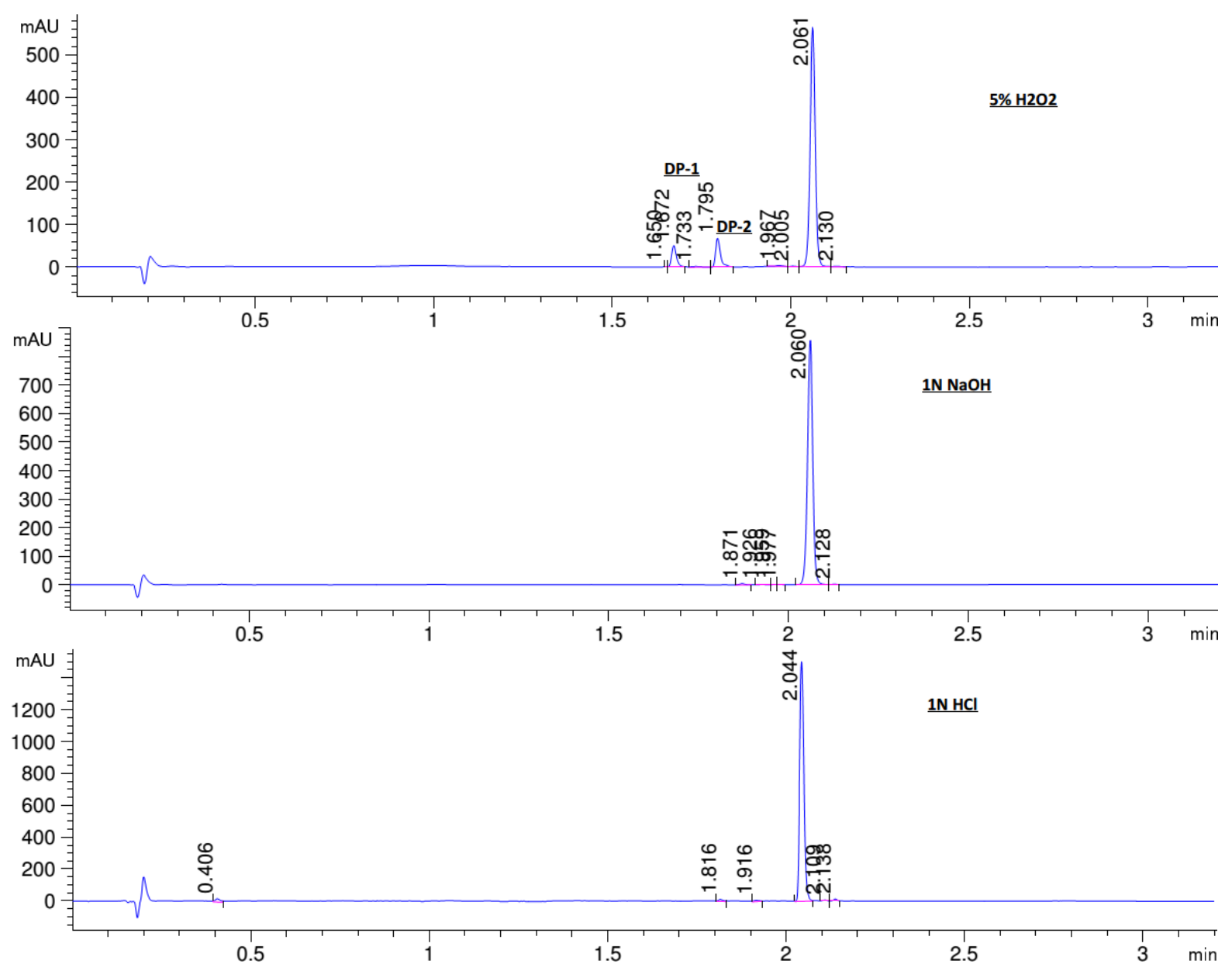

Fig.-1: Acid, Base and Oxidation Degradation Chromatograms of Itraconazole Drug Substances

\section{Isolation of Peroxide Degradation Products}

Lyophilization /Purification procedure was adopted to isolate the two degradants from the corresponding fractions and named as DP-1 \& DP-2, later structural elucidation was performed by using 1D \& 2D NMR spectroscopic studies and HRMS analysis. The identified impurity structures were verified against the Literature search and found to be new products.Structures of Itraconazole and degradation products DP-1 and DP-2 were shown in (Fig.-2).

\section{MS/MS Analysis}

After conducting the mass spectrometric analysis on Itraconazole and its isolated degradation products the Reasonable fragmentation pathways of Itraconazole drug substance and its degradation products(DP1,DP-2) were captured in (Fig.-3), (Fig.-4) and (Fig.-5)

\section{Structure Elucidation of DP-1}

The HRMS showed a protonated molecular ion peak at $\mathrm{m} / \mathrm{z} 737.2383[\mathrm{M}+\mathrm{H}]^{+}$corresponding to molecular formula $\mathrm{C}_{35} \mathrm{H}_{39} \mathrm{Cl}_{2} \mathrm{~N}_{8} \mathrm{O}_{6}$. This mass data indicating that 32 mass units higher than drug(ITRACONAZOLE) mass 704.The ${ }^{1} \mathrm{H}$ NMR spectrum revealed that the DP-1 had 24 aliphatic protons, 14 aromatic protons .The ${ }^{13} \mathrm{C}$ NMR spectrum showed 13 aliphatics carbon and 22 aromatic carbons. 1H, 13C chemical shift values for DP1 was assigned by using 1H,13C, HSQC and HMBC Experiments. The assignments of DP-1 are shown in Table-1. A number of protons and carbons observed same as like drug but few protons and few carbons chemical shift values were drastically changed compare to the drug. 30,32 position proton chemical shift values were moved to downfield $4.88 \mathrm{ppm}$ from $3.32 \mathrm{ppm}$ (drug). 35,39 position aromatic proton chemical shift values were moved to downfield $8.34 \mathrm{ppm}$ 
RASĀYAN J. Chem.

Vol. 12 | No. 1 |114 - 122| January - March | 2019

from 7.1ppm(drug). 36,38 position aromatic proton chemical shift values were moved to downfield 7.92 ppm from 7.51ppm(drug). These proton chemical shift value changes indicating that oxygen attacked on $31^{\text {st }}$ position nitrogen. 30,32 position carbon chemical shift values were moved to downfield $63.4 \mathrm{ppm}$ from 48.2ppm(drug). These carbon chemical shift value changes also indicating that oxygen attacked on $31^{\text {st }}$ position nitrogen.

Table - 1: ${ }^{1} \mathrm{H},{ }^{13} \mathrm{C}$ NMR Data of Itraconazole Drug Substance and Degradation Products DP-1 and DP-2

\begin{tabular}{c|c|c|c|c|c|c|c}
\hline \multirow{2}{*}{ Assignment } & $\begin{array}{c}\text { Type of } \\
\text { Atom }\end{array}$ & $\begin{array}{c}{ }^{1} \mathrm{H}(\mathrm{PPM}) \\
\text { Drug }\end{array}$ & $\begin{array}{c}{ }^{13} \mathrm{C}(\mathrm{PPM}) \\
\text { Drug }\end{array}$ & $\begin{array}{c}{ }^{1} \mathrm{H}(\mathrm{PPM}) \\
\mathrm{DP}-1\end{array}$ & $\begin{array}{c}{ }^{33} \mathrm{C}(\mathrm{PPM}) \\
\mathrm{DP}-1\end{array}$ & $\begin{array}{c}{ }^{1} \mathrm{H}(\mathrm{PPM}) \\
\mathrm{DP}-2\end{array}$ & $\begin{array}{c}{ }^{13} \mathrm{C}(\mathrm{PPM}) \\
\mathrm{DP}-2\end{array}$ \\
\hline 1 & $\mathrm{C}$ & & 132.5 & & 132.5 & & 132.6 \\
\hline 2 & $\mathrm{CH}$ & 7.67 & 130.5 & 7.68 & 130.6 & 7.67 & 130.7 \\
\hline 3 & $\mathrm{C}$ & & 134.4 & & 134.4 & & 134.5 \\
\hline 4 & $\mathrm{CH}$ & 7.42 & 127.2 & 7.43 & 127.3 & 7.43 & 127.2 \\
\hline 5 & $\mathrm{CH}$ & 7.5 & 129.9 & 7.51 & 130.1 & 7.5 & 130.1 \\
\hline 6 & $\mathrm{C}$ & & 134.9 & & 134.9 & & 134.9 \\
\hline 7 & $\mathrm{C}$ & & 107.2 & & 107.4 & & 107.3 \\
\hline 11 & $\mathrm{CH}$ & 4.36 & 74.7 & 4.42 & 74.8 & 4.41 & 74.6 \\
\hline 12 & $\mathrm{CH} 2$ & $3.74,3.92$ & 66.6 & $3.78,3.93$ & 66.6 & $3.77,3.93$ & 66.4 \\
\hline 14 & $\mathrm{CH} 2$ & 4.81 & 53.1 & 4.83 & 53.2 & 4.82 & 53.2 \\
\hline 16 & $\mathrm{CH}$ & 8.42 & 145.4 & 8.42 & 145.3 & 8.41 & 145.5 \\
\hline 18 & $\mathrm{CH}$ & 7.88 & 150.7 & 7.87 & 150.7 & 7.86 & 150.7 \\
\hline 20 & $\mathrm{CH} 2$ & 3.72 & 67.7 & $3.87,3.93$ & 67.9 & $3.86,3.89$ & 67.8 \\
\hline 22 & $\mathrm{C}$ & & 151.9 & & 158.2 & & 158.2 \\
\hline 23,27 & $\mathrm{CH}$ & 6.86 & 115.1 & 7.08 & 114.5 & 7.03 & 114.4 \\
\hline 24,26 & $\mathrm{CH}$ & 6.97 & 117.6 & 8.12 & 122 & 8.08 & 122.2 \\
\hline 25 & $\mathrm{C}$ & & 145.6 & & 147.7 & & 147.6 \\
\hline 29,33 & $\mathrm{CH} 2$ & 3.18 & 49.5 & 3.14 & 63.4 & $3.19,4.13$ & 66.1 \\
\hline 30,32 & $\mathrm{CH} 2$ & 3.32 & 48.2 & 4.88 & 63.4 & $3.64,3.71$ & 43.5 \\
\hline 34 & $\mathrm{C}$ & & 149.8 & & 152.8 & & 149 \\
\hline 35,39 & $\mathrm{CH}$ & 7.1 & 115.7 & 8.34 & 121.9 & 7.16 & 116 \\
\hline 36,38 & $\mathrm{CH}$ & 7.51 & 122.9 & 7.92 & 121.7 & 7.54 & 123 \\
\hline 37 & $\mathrm{C}$ & & 125.5 & & 134.5 & & 126 \\
\hline 41 & $\mathrm{CH}$ & 8.34 & 135 & 8.57 & 134.6 & 8.35 & 135.1 \\
\hline 44 & $\mathrm{C}=\mathrm{O}$ & & 151.3 & & 150.9 & & 151.4 \\
\hline 46 & $\mathrm{CH}$ & 4.13 & 51.7 & 4.17 & 52.1 & 4.12 & 51.8 \\
\hline 47 & $\mathrm{CH} 2$ & 1.69 & 27.9 & $1.67,1.72$ & 27.9 & $1.65,1.71$ & 27.9 \\
\hline 48 & $\mathrm{CH} 3$ & 0.79 & 10.6 & 0.80 & 10.6 & 0.79 & 10.7 \\
\hline 49 & $\mathrm{CH} 3$ & 1.29 & 19.2 & 1.30 & 19.3 & 1.28 & 19.3 \\
\hline & & & & & &
\end{tabular}

29,33 position proton chemical shift values were moved to up field $3.14 \mathrm{ppm}$ from 3.18ppm(drug). 24,26 position aromatic proton chemical shift values were moved to downfield $8.12 \mathrm{ppm}$ from $6.97 \mathrm{ppm}$ (drug). 23,27 position aromatic proton chemical shift values were moved to downfield 7.08 ppm from $6.86 \mathrm{ppm}$ (drug).These proton chemical shift value changes indicating that oxygen attacked on $28^{\text {th }}$ position nitrogen. 29,33 position carbon chemical shift values were moved to downfield $63.4 \mathrm{ppm}$ from $49.5 \mathrm{ppm}$ (drug). These carbon chemical shift value changes also indicating that oxygen attacked on $28^{\text {th }}$ position nitrogen. Thus two oxygen atoms attacked on the molecule, one oxygen attacked on $28^{\text {th }}$ position nitrogen and another oxygen attacked on $31^{\text {st }}$ position nitrogen. HRMS, 1D,2D NMR data matched with the structure as shown in (Fig.-2).

\section{Structure Elucidation of DP-2}

The High-resolution MS data revels that the molecular ion peak at $\mathrm{m} / \mathrm{z}$ value $721.2430[\mathrm{M}+\mathrm{H}]^{+}$is attributed to a molecular formula of $\mathrm{C}_{35} \mathrm{H}_{39} \mathrm{Cl}_{2} \mathrm{~N}_{8} \mathrm{O}_{5}$. This mass data indicating that 16 mass units higher than drug(ITRACONAZOLE) mass 704.The ${ }^{1} \mathrm{H}$ NMR spectrum revealed that the DP-2 had 24 aliphatic 
protons, 14 aromatic protons .The ${ }^{13} \mathrm{C}$ NMR spectrum showed 13 aliphatics carbon and 22 aromatic carbons. 1H, 13C chemical shift values for DP2 was assigned by using ${ }^{1} \mathrm{H},{ }^{13} \mathrm{C}$, HSQC and HMBC Experiments. The assignments of DP-2 are shown in Table 1. A number of protons and carbons observed same as like drug but few protons and few carbons chemical shift values were drastically changed compare to the drug. 29,33 position proton chemical shift values were moved to downfield $3.19 \mathrm{ppm}, 4.13 \mathrm{ppm}$ from 3.18ppm(drug).

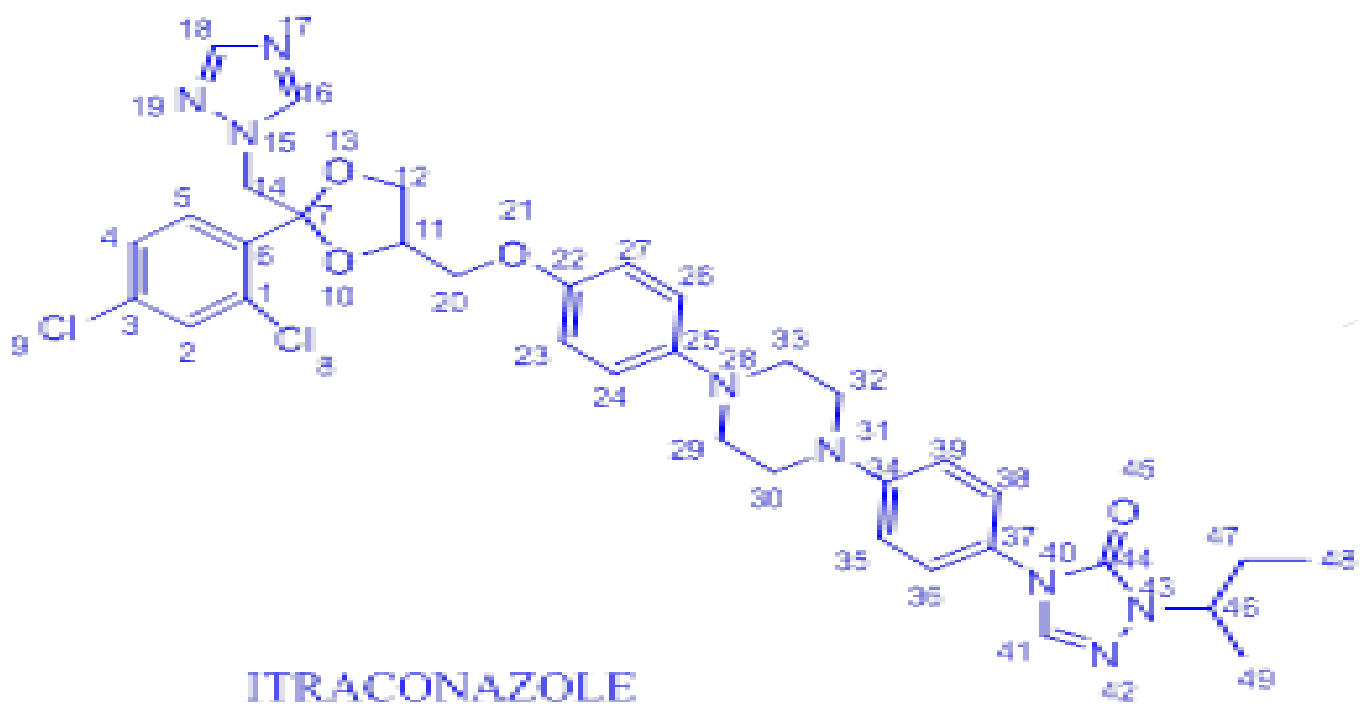

Chenical Fommila: $\mathrm{C}_{35} \mathrm{H}_{35} \mathrm{Cl}_{2} \mathrm{~N}_{8} \mathrm{O}_{4}$

Exact Mass: 704.24

Molecular Wejght: 705.64

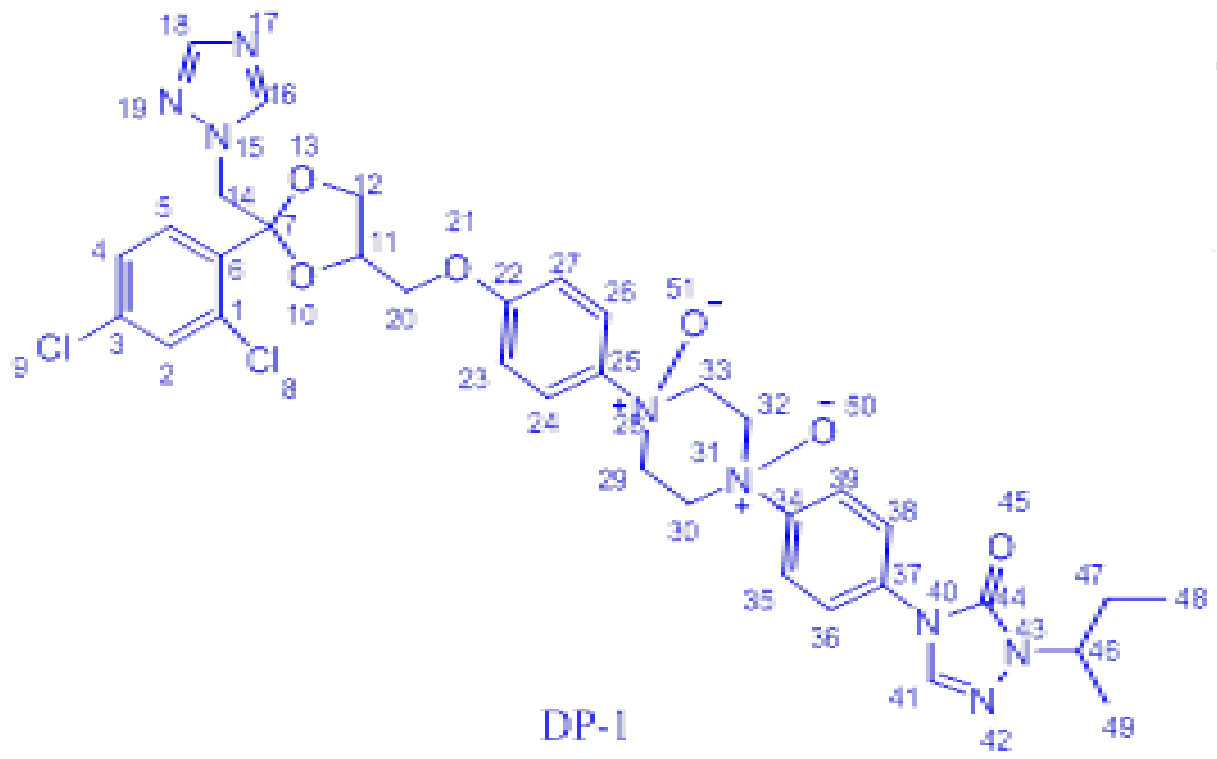

Chemical Fommula: $\mathrm{C}_{35} \mathrm{H}_{35} \mathrm{Cl}_{2} \mathrm{~N}_{8} \mathrm{O}_{6}$

Exact Mass: 736.23

Molecular Weight: 737.64 
RASĀYAN J. Chem.

Vol. 12 | No. 1 |114 - 122| January - March | 2019

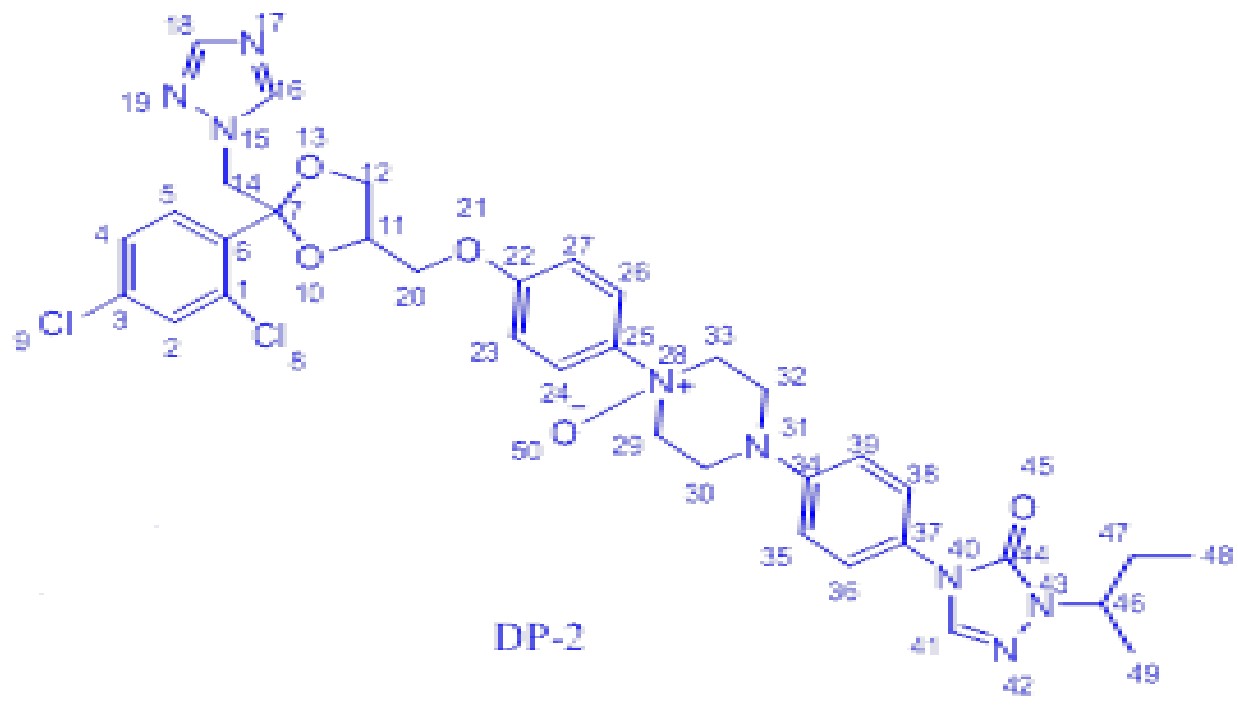

Chemical Formula: $\mathrm{C}_{35} \mathrm{H}_{3}, \mathrm{Cl}_{2} \mathrm{~N}_{8} \mathrm{O}_{5}$

Exact Mass: 720.23

Molecular Weight: 721_64

Fig.-2: Structures of Itaconazole and its Degradation Products

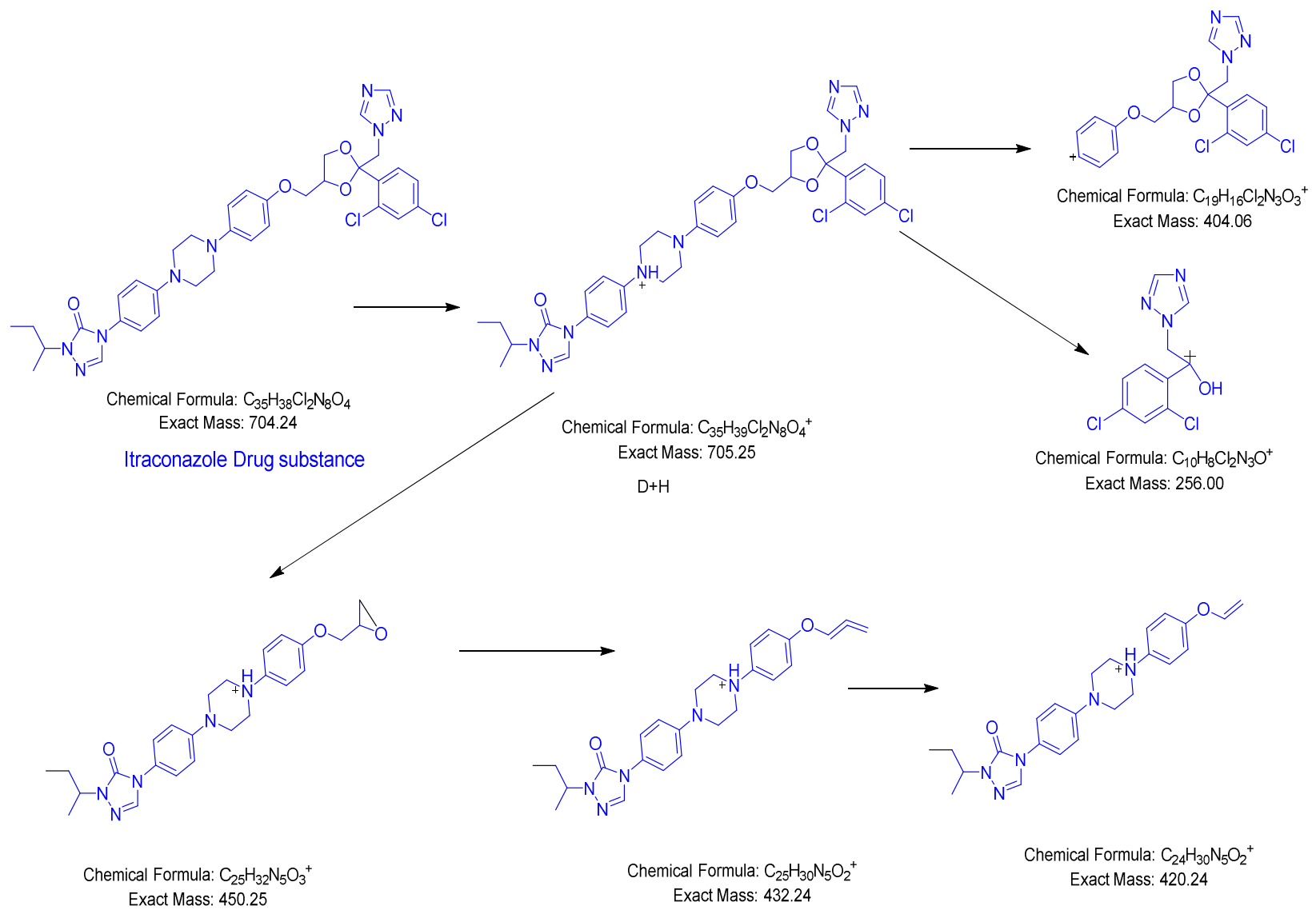

Fig.-3: Probable Fragmentation Pathway of Itraconazole Drug Substances 
RASĀYAN J. Chem.

Vol. 12 | No. 1 |114 - 122| January - March | 2019
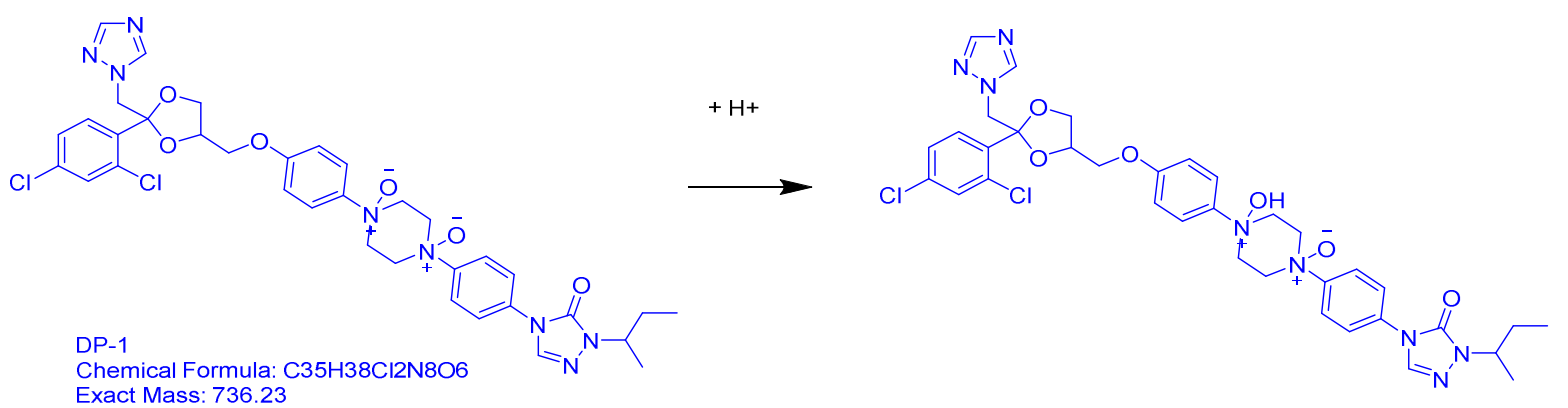

Exact Mass: 736.23
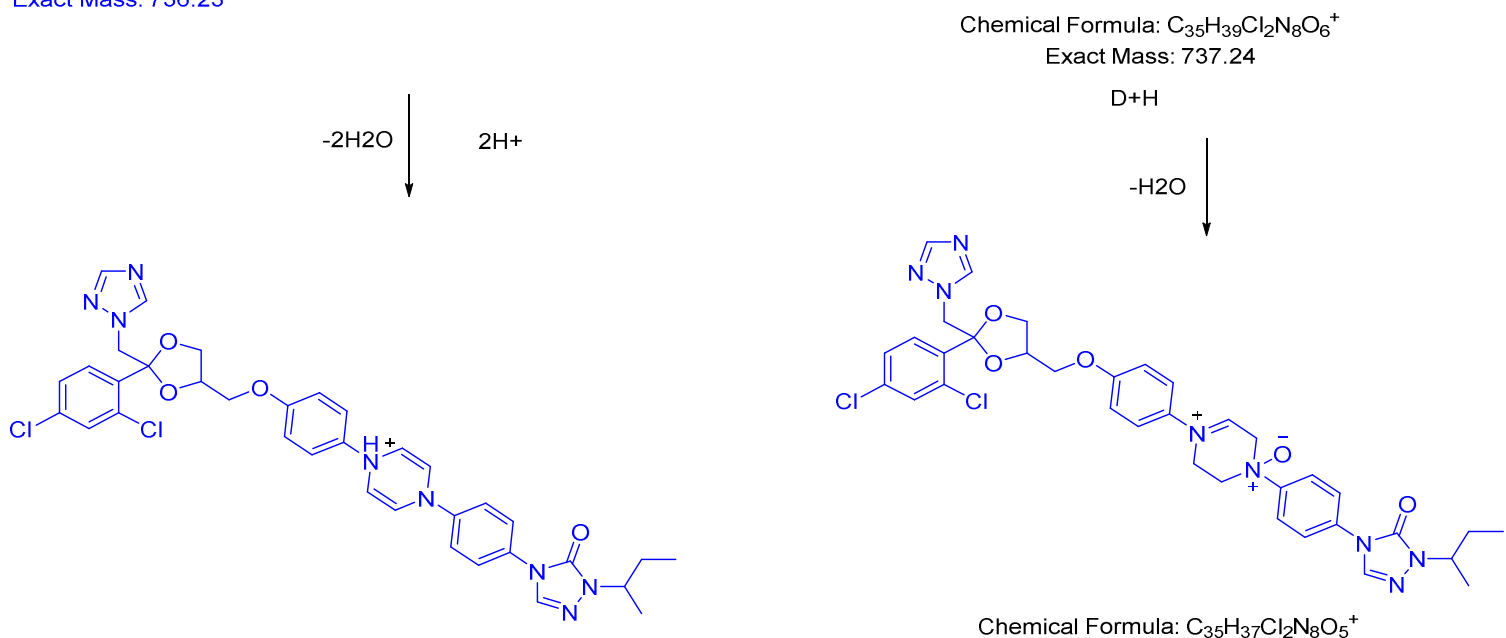

Chemical Formula: $\mathrm{C}_{35} \mathrm{H}_{35} \mathrm{Cl}_{2} \mathrm{~N}_{8} \mathrm{O}_{4}{ }^{+}$

Chemical Formula: $\mathrm{C}_{35} \mathrm{H}_{37} \mathrm{Cl}_{2} \mathrm{~N}_{8} \mathrm{O}_{5}{ }^{+}$ Exact Mass: 701.22

Exact Mass: 719.23

Fig.-4: Probable Fragmentation pathway of DP-1

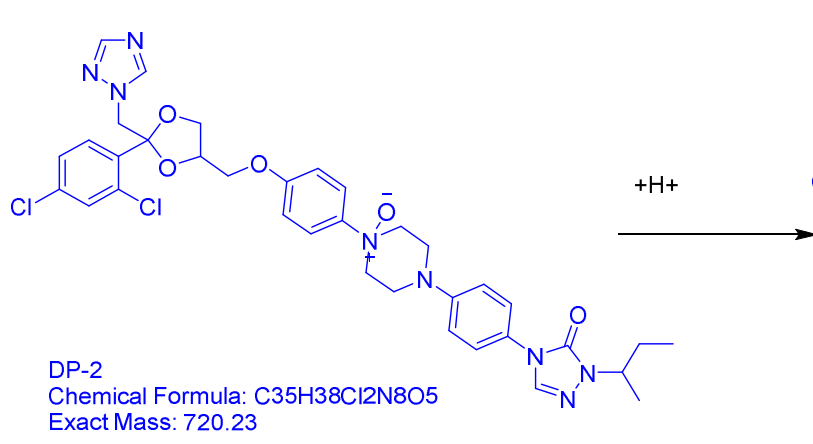

Exact Mass: 720.23
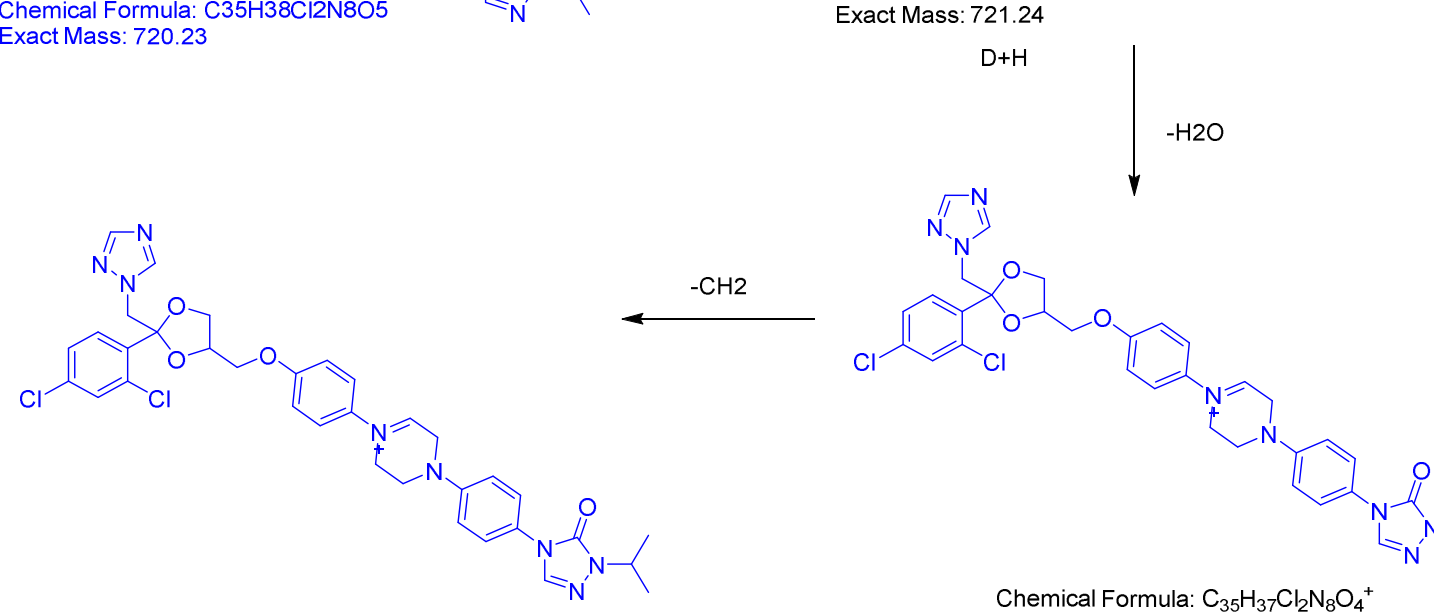

Chemical Formula: $\mathrm{C}_{34} \mathrm{H}_{35} \mathrm{Cl}_{2} \mathrm{~N}_{8} \mathrm{O}_{4}{ }^{+}$

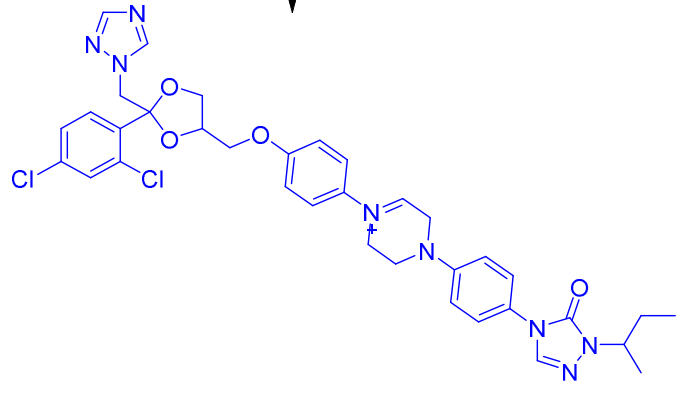

Chemical Formula: $\mathrm{C}_{35} \mathrm{H}_{37} \mathrm{Cl}_{2} \mathrm{~N}_{8} \mathrm{O}_{4}^{+}$

Exact Mass: 703.23

Exact Mass: 689.22

Fig.-5: Probable Fragmentation pathway of DP-2 
RASĀYAN J. Chem.

Vol. 12 | No. 1 |114 - 122| January - March | 2019

24,26 position aromatic proton chemical shift values were moved to downfield 8.08 ppm from $6.97 \mathrm{ppm}$ (drug). These proton chemical shift value changes indicating that oxygen attacked on $28^{\text {th }}$ position nitrogen. 29,33 position carbon chemical shift values were moved to downfield $66.1 \mathrm{ppm}$ from $49.5 \mathrm{ppm}$ (drug). These carbon chemical shift value changes also indicating that oxygen attacked on $28^{\text {th }}$ position nitrogen. HRMS, 1D,2D NMR data matched with the structure as shown in (Fig.-2) for DP-2. A plausible mechanism for the formation of degradation products DP-1 and DP-2 from itraconazole drug substance during oxidation was shown in (Fig.-6).

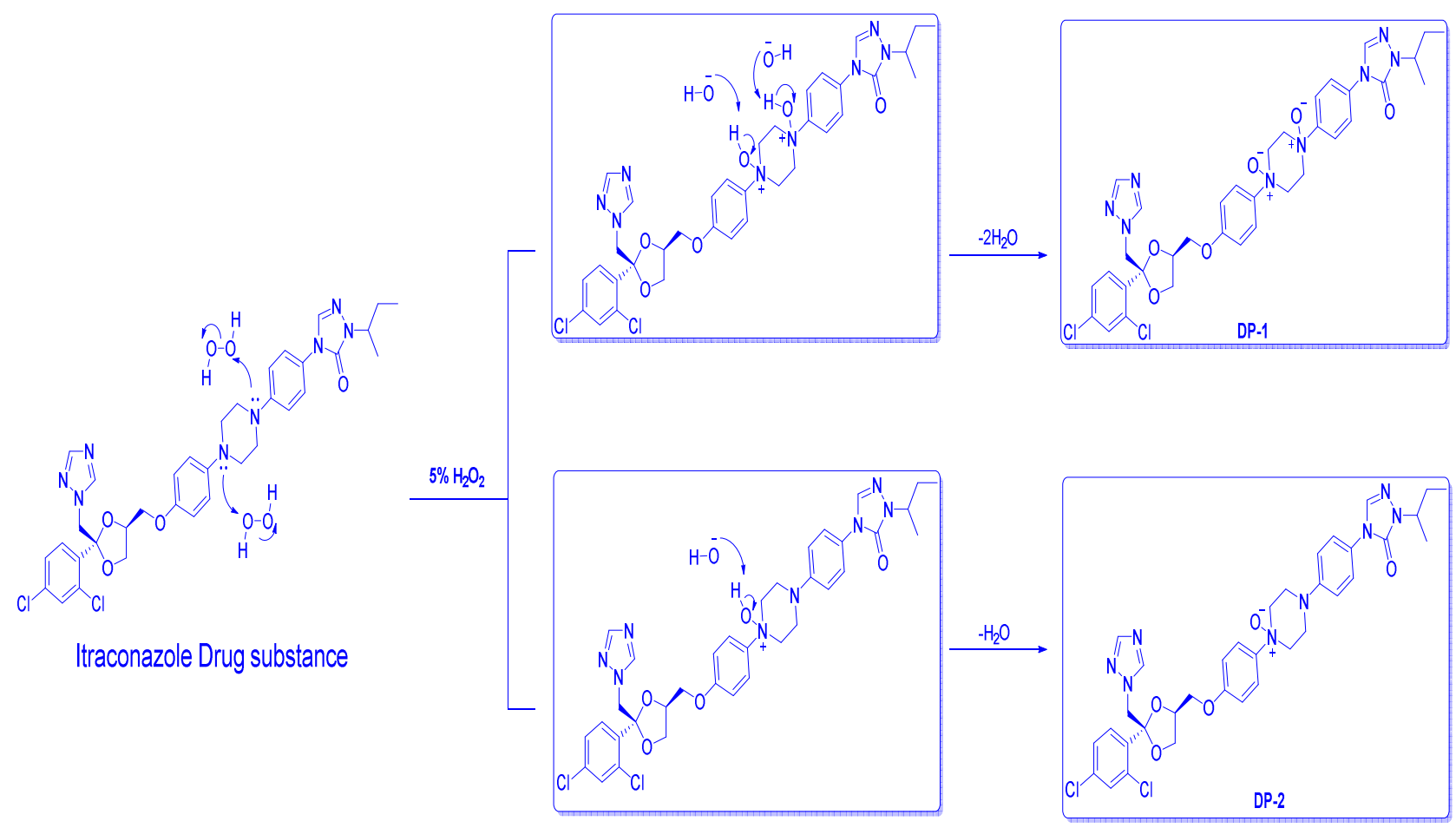

Fig.-6: Probable Mechanism for Formation of DP-1 and DP-2 during Oxidation

\section{CONCLUSION}

When the drug was subjected to oxidation, two novel degradant products were observed. These two degradant products structures were confirmed by HRMS and NMR data wise. These products so far not published in any journal as per our literature search.

\section{ACKNOWLEDGMENT}

Sincere thanks to the management of GVK Biosciences Pvt. Ltd for this study /for their continuous support.

\section{REFERENCES}

1. CPMP. Note for Guidance on Stability Testing: Stability Testing of Existing Active Substances and Related Finished Products. Committee for Proprietary Medicinal Products, EMEA, London (2002)

2. ICH guideline. Q1A (R2) stability testing of new drug substances and products. In: International Conference on Harmonisation, IFPMA, Geneva (2003).

3. WHO. Stability Testing of Active Pharmaceutical Ingredients and Pharmaceutical Products. World Health Organization: Geneva (2007).

4. K. M. Alsante, L. Martin, S.W. Baertschi, Pharmaceutical Technology, 27, 60(2003).

5. M. Bakshi and S. Singh, Journal of Pharmaceutical and Biomedical Analysis, 28, 1011(2002).

6. A. Kryczyk, P. Żmudzki, U. Hubicka, Biomedical Chromatography, 30, 1733(2016). 
RASĀYAN J. Chem.

Vol. 12 | No. 1 |114 - 122| January - March | 2019

7. A.M. Badawey, N.T. Lamie, B.A.El.A.Abd El-Aziz, Analytical Chemistry an Indian Journal, 12, 48(2013).

8. S.K. Parikh, J.B. Dave, C.N. Patel, B. Ramalingan, Pharmaceutical Methods, 2, 88(2011).

9. S. Paruchuri and K.H. Pavani, Indian Journal of Research in Pharmacy and Biotechnology, 1, 857(2013).

10. B.S. Kapoor and G.V. Subbarao, International Journal of Pharmaceutical Sciences and Nanotechnology, 4, 1497(2011).

11. V. Verma, and S.U. Kumar, Journal of Chemical and Pharmaceutical Research, 8, 58(2016).

12. M.A. Mirza, T. Sushama, Z. Iqbal, Journal of Liquid Chromatography \& Related Technologies, 35, 1459(2012).

13. M.M. Abou El Alamin, D. Mohamed, M. Marwa, M. Azab, Analytical Chemistry Letters, 6, 748(2016).

[RJC-5077/2018] 